\title{
The Stage Characteristics and Transformation Strategy Choice of Shandong's Economic Development
}

\author{
Yuezhou Hu*, Long Lin \\ Chung-Ang University, Seoul, South Korea \\ E-mail: caosha42782@163.com.
}

\begin{abstract}
This article focuses on the detailed analysis of Shandong's economic development. First, it analyzes the stage characteristics of Shandong's economic development. Secondly, it points out the problems existing in Shandong's economic transformation and development. Finally, it puts forward several strategies for Shandong's economic transformation and development. The author hopes that the research in this article can contribute to the sound development of Shandong's economy.
\end{abstract}

Keywords: Shandong's economic development, stage characteristics, transformation strategy choice

\section{Introduction}

In recent years, China's development has gradually entered a new stage. At this stage, the economic development of all regions has been affected to a certain extent. This influence will increase the overall pressure on regional economic development, which is not conducive to the overall progress of modern society. And Shandong Province also has many problems under this influence. At present, Shandong Province has significant economic problems. If this continues, the competition level of Shandong Province in the contemporary market will inevitably decrease. Therefore, it is necessary to intensify the research on the stage characteristics of Shandong's economic development and the choice of transition strategies.

\section{The stage characteristics of Shandong's economic development}

\subsection{The first stage}

The so-called first stage refers to the period from 1978 to 1985, when Shandong's economy was in a stage of rapid development. With the deepening of the economic system reform, the market system began to flourish on the margins of the traditional planned economic system. During this period, Shandong had obvious advantages in agriculture and light industry, the county economy was developed, and township and village enterprises emerged as a new force with strong economic vitality. A large number of enterprises such as Haier, Hisense, Weiqiao, and Xiwang have begun to stand out in the country, which has promoted the rapid rise of the province's economy. At that time, the industrial structure of Shandong's economy was dominated by the first and second types of industries. The light industry accounts for a larger proportion of the secondary industry, and the total amount of the tertiary industry is relatively small. During this period, the overall trajectory of Shandong's economic development and national economic development was consistent, and Shandong's economy was the leader in national economic development.

\subsection{The second stage}

The so-called second stage refers to the period from 1986 to 2001, when Shandong's economy was in a stage of steady growth. Relying on advantageous resources, demographic dividends, and industrial foundation, Shandong Province has continuously absorbed advanced foreign technologies and achieved sustained economic growth in the province. During this period, Shandong private enterprises developed rapidly. In 1992, Shandong Province had 10,000 private enterprises, ranking fourth in the country. At the same time, the economic structure of Shandong Province has also undergone major changes. The proportion of secondary and tertiary industries has continued to increase, and heavy industries such as petrochemicals and steel have developed rapidly and have become the province's pillar industries. The changes in the economic structure of Shandong Province are basically consistent with the overall path of national economic development, and the comparative advantages of economic development have gradually emerged. Shandong has become one of the country's largest industrial bases. 


\subsection{The third stage}

The so-called third stage refers to the period from 2002 to 2008, when Shandong's economy was in a hidden danger stage. During this period, the revolution of the Internet information industry came quietly. A large number of Internet companies have risen rapidly. The four cities of Beijing, Shanghai, Guangzhou and Shenzhen have undergone structural transformations in due course, and their economic vitality is remarkable. At this time, the Internet economy and modern service industry are developing rapidly, and the proportion of the tertiary industry is gradually increasing. However, Shandong's economic growth still relies on heavy chemicals, with cement, steel, petroleum, and chemical production ranking among the top three in the country. The industrial structure is still dominated by traditional industries, the tertiary industry has developed slowly, and the development of modern service industries has been lagging behind, which has missed opportunities for economic transformation. Although the extensive growth method maintained the apparent prosperity of Shandong's economy, it also laid hidden dangers for the subsequent economic recession.

\subsection{The fourth stage}

The so-called fourth stage refers to the period from 2009 to 2021, when Shandong's economy is in the transitional development stage. During this period, the national economy entered a stage of high-quality development, the industrial structure tended to be service-oriented, and the dominant position of the service industry was very obvious. The development of the "three highs" (high pollution, high energy consumption, and high water consumption) industries is limited, and the "four new" (new technologies, new industries, new formats, and new models) are developing rapidly. At this stage, the tertiary industry in Shandong Province's share of GDP has increased, and the industrial structure has been gradually optimized. However, Shandong's economic growth still relies on traditional industries, and the development of modern service industries lags behind Guangdong, Jiangsu, Zhejiang and other regions. Various reasons have led to the slow economic transformation of Shandong.

\section{Problems existing in Shandong's economic transformation}

\subsection{Heavy industry accounts for a relatively large proportion}

From the perspective of the comprehensive development of Shandong's heavy industry, it is not difficult to see that Shandong's heavy industry is showing a trend of accelerated development. At the beginning of reform and opening up, the proportion of heavy industry in Shandong Province was 46.0\%. However, 15 years later, the proportion of heavy industry was only $50.6 \%$, and the proportion of full-process industry only increased by $4.6 \%$. During the "Ninth Five-Year Plan" period, Shandong's heavy industry developed rapidly. The proportion of heavy industry rose from 50.6\% in 1995 to $60.1 \%$ in 2000 , an increase of $9.5 \%$ in just five years. Subsequently, Shandong Province continued to accelerate the development of heavy industry, the proportion of heavy industry increased from $60.1 \%$ to $65.1 \%$ in 2005 , and the proportion increased by $5 \%$ within five years. So far, Shandong's heavy industry has maintained a relatively rapid and sustainable development, which means that the proportion of heavy industry will continue to increase.

\subsection{The development of modern service industry is lagging behind}

Judging from the development status of Shandong's modern service industry, Shandong's modern service industry clusters such as information transmission and software services are small in scale and weak in innovation. The modern service industry has a relatively shallow level of integration with other industries, and the integrated development of the productive service industry that serves product research and innovation and technological process improvement is relatively lagging. Shandong's modern service industry companies have a low market share and increased costs, which are difficult to pass on, resulting in low corporate efficiency and the overall industry profit growth rate is lower than the income growth rate. On the whole, Shandong's modern service industry has developed slowly, with poor quality and low efficiency, resulting in the stagnation of the income of the residents of the province, a sharp drop in effective demand, limited consumption motivation of residents, and the overall economic development of the province slowing down.

\subsection{The private economy is underdeveloped}

From the perspective of financing, Shandong's total loan volume and growth rate are lower than those of Jiangsu, Zhejiang and Guangdong. More than $50 \%$ of the capital flows to large state-owned enterprises and state-owned holding companies. The amount of private financing is small, and there are very few medium-sized and micro-enterprises. From the perspective of talent flow, Shandong Province has a serious population exodus. Higher-level talents mostly flow to government departments, institutions or state-owned enterprises, and local private enterprises have difficulty attracting talents. From the perspective of enterprise management system, many large private enterprises in Shandong 
Province originated from the restructuring of state-owned enterprises or collective enterprises. They have followed the original organizational arrangements of state-owned enterprises or collective enterprises, and are often affected by strong administrative intervention by local government departments. This has led to severe institutional and administrative dependence.

\section{Shandong's economic transformation and development strategy}

\subsection{Take advantage of local conditions}

According to the gap between the existing industries in Shandong Province and the domestic and international frontiers, combined with the characteristics of the economic development of Shandong Province at this stage, Shandong enterprises are divided into the following types. (1) Strategic type. Industries such as offshore oil, offshore engineering equipment, and supercomputers are strategic industries in Shandong Province. These industries are related to my country's national defense security and have the characteristics of a long research and development cycle, large capital investment, inability to completely rely on the market, and the need for government to provide financial subsidies. Shandong should actively encourage the development of supporting industries, improve the level of infrastructure construction, and achieve mutual benefit and win-win results between strategic industries and other local industries. (2) Elimination type. Obsolete industries refer to industries that do not conform to the overall development trajectory of the region, have overcapacity, or lose their comparative advantages. According to the characteristics of the economic development of Shandong Province at this stage, low-end salt chemical industry, local smelting, small steel and other high-pollution and high-energy industries are among the eliminated industries. (3) Potential type. Industries whose existing industrial technology and added value are below the cutting-edge level are called potential industries. Through the analysis of the resource endowment of Shandong Province, industries such as biomedicine, new energy vehicles, and high-end equipment manufacturing are potential industries in Shandong Province. For these industries, Shandong should strengthen financial support, broaden financing channels, support cross-border mergers and acquisitions of similar advanced technology companies, strengthen cooperation with overseas scientific research institutions, attract high-end talents, set up R\&D centers, and improve its own innovation efficiency.

\subsection{Promote industrial integration and develop modern service industry}

The level of development of the service industry is an important indicator of economic development. The development of the service industry is currently an important measure to reduce the level of energy consumption. In the absence of major breakthroughs in energy-saving technology, the potential to reduce the level of energy consumption per unit of production is limited. The most important thing is to adjust the economic structure and further accelerate the development of low energy consumption industries. According to statistics, the service industry has an average annual growth rate of $1 \%$, and the energy consumption of each unit's GDP in Shandong Province will drop by about $1.2 \%$ year by year. Therefore, it is very important to accelerate the development of the service industry and increase the proportion of the service industry in the national economy. Shandong Province should innovate development concepts, optimize the development environment, develop modern service industries such as finance, logistics, and insurance, and strive to increase the proportion of service industries in regional GDP, and create more social wealth with less energy input. In addition, the benefits of Shandong's agriculture can also be fully utilized when promoting industrial integration and developing modern service industries. Combining with the implementation of rural revitalization strategy, with the goal of creating a suitable integrated development environment, promoting the development of modern service industry and agriculture. Vigorously develop the integration of agricultural industry; develop agricultural tourism, agricultural logistics, agricultural science and technology services, agricultural information services and other productive service industries; promote the integration of modern service industries and agriculture; give full play to the externalities of modern services.

\subsection{Actively guide the development of the private economy}

The private economy is the main force of Shandong's economic development. Therefore, based on the characteristics of economic development at this stage, the role of private enterprises should be brought into play to solve the problems of private enterprises' financing difficulties, lack of talents, and weak technology, so as to improve the viability of private enterprises and strengthen the economy. The vitality of the market. The specific strategy is as follows. (1) Actively integrate financial resources and expand financing channels for small and medium-sized private enterprises. Based on the flow of funds and goods between private enterprises, it provides quasi-credit financing for private enterprises, and solves the problems of unsecured suppliers of private enterprises and weak credit entities. Based on high-tech such as big data and 
cloud computing, we will comprehensively and accurately characterize private enterprises to improve the convenience and pertinence of private enterprises' financing. (2) Encourage private enterprises to carry out technological innovation. Build a technological innovation platform to reduce the innovation cost of private enterprises. Support private enterprises to enter a new economy characterized by new technologies, new industries, new business forms and new models. Promote "flagship" private enterprises with comparative advantages, follow the law of industrial evolution, and guide enterprises to take the initiative to transform.

\section{Conclusion}

In summary, Shandong Province has completely entered a transitional stage in terms of economy. At this time, if Shandong Province cannot fundamentally solve the problems of heavy industry, the lagging development of modern service industry, and the lagging development of private economy, it will inevitably lead to an infinite slowdown in the speed of transformation. Therefore, in the process of economic transformation, Shandong Province should actively implement strategies to take advantage of local conditions, promote industrial integration, develop modern service industries, and actively guide the development of the private economy, so as to transform the entire region's economic transformation into targeted transformations in each part., So that economic transformation can get more impetus.

\section{References}

[1] Liu Lei, Xia Yong. Strategic choice and stage characteristics: the gradual path of green transformation of China's industrialization. Economic System Reform. 2020; 225(06): 110-116.

[2] Fu Wangqiang, Wu Chunya, Xie Yuantai. Phase analysis of the 70-year economic growth mode transformation of New China. Frontiers of Social Sciences. 2020; 9(6): 10-10.

[3] Liu Jianzhi, Fang Yangang, Wang Ruru. Analysis of the temporal and spatial evolution characteristics and driving mechanism of agricultural multi-function in Shandong Province. Journal of Natural Resources. 2020; 35(12): 83-97.

[4] Zhang Feng, Liu Xiyuan, Wu Lidong. Product innovation or service transformation: economic policy uncertainty and manufacturing innovation choices. China Industrial Economics. 2019; (7): 101-118.

[5] Chen Feiyu, Wang Tan. The integration of higher education into the "Belt and Road" economic development and path selection: Taking Shandong Province as an example. Shandong Social Sciences. 2019; 281(01): 182-187.

[6] Li Zhibing, Shu Li. Science and Technology Progress and the Transformation and Optimization of China's Economic Development Mode - Comment on "Science and Technology Progress and the Transformation of China's Economic Development Mode". Science and Technology Progress and Policy. 2020; 493(09): 168-168. 